\title{
Coming full circle: patient and physician reunite in kidney research network
}

\author{
David Collister MD PhD, Arlene Desjarlais
}

Cite as: CMAJ 2021 November 8;193:E1693-4. doi: 10.1503/cmaj.210426

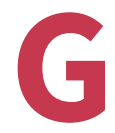

len Desjarlais was a 53-year-old Métis man with kidney failure due to diabetic nephropathy, who started hemodialysis in 2012. He received in-centre hemodialysis 3 times a week via a right tunnelled catheter and was considering home hemodialysis, which would be performed by his wife. He was on the waiting list for a deceased donor kidney transplant.

In May 2015, Glen had a myocardial infarction, after which he underwent uncomplicated coronary artery bypass grafting. While in hospital, he received hemodialysis 3 times a week and he was to be discharged when he was at his baseline functional status.

\section{Spouse's perspective}

I am the proud wife of my beloved husband, Glen, who passed away on February 18, 2016. Glen had many health issues, including diabetes, heart and kidney disease. During Glen's lengthy illness, I was there for every treatment, appointment and procedure, no matter how big or small. Over time, I gained confidence as his advocate and was able to build a wonderful relationship with his care team.

After Glen had bypass surgery, we were waiting to be discharged on a Saturday. The nephrology resident, Dr. Collister, whom I hadn't met before, provided us with Glen's discharge plan. He told us that Glen's next scheduled dialysis session was Monday. I immediately realized that if we waited until Monday, Glen would not have been dialyzed for 3 days - I knew he could potentially be fluid overloaded by then. There was no way I was going to allow him to wait until Monday for treatment.

After some increasingly heated back and forth, I sternly suggested that Dr. Collister call the dialysis unit. After he left the room, Glen shook his head, saying, "You can't talk to him like that." I explained to Glen he couldn't wait until Monday. Glen always chose to pretend all was fine and he could just wait his turn for things - he lived in denial.

I called the dialysis unit and spoke with a nurse who knew Glen and me. She confirmed he was scheduled for dialysis on
Saturday. I don't know where the disconnect happened about his next dialysis treatment. All I knew was that Glen was going to receive the treatment he needed and we could finally go home. After my call, Dr. Collister explained to Glen that I was correct and that he would be receiving treatment that evening. We thanked Dr. Collister for everything and he wished us nothing but the best.

\section{It was the strong relationships I'd built with Glen's care team that gave me the comfort to use my voice as a caregiver that day.}

Three years later, I unexpectedly found myself face to face with Dr. Collister at the annual meeting of the Can-SOLVE CKD Network (a Canadian group doing research on kidney disease). We recognized each other immediately. I felt embarrassed and apologized for my behaviour that morning, 3 years before.

He told me I had nothing to apologize for. "Because of you, I am a better doctor. I listen to my patients when they speak up. Your persistence that day taught me that."

I was shocked. I can't imagine what might have happened to Glen if I hadn't felt comfortable enough to stand my ground and call the unit myself. I know now it was the strong relationships I'd built with Glen's care team that gave me the comfort to use my voice as a caregiver that day. I have always said I never wanted Glen to be just a statistic. I want his death to mean something. I want people to learn from our journey. 


\section{Physician's perspective}

When I was a nephrology fellow, I took care of Glen for several days when he was an inpatient undergoing coronary artery bypass grafting. I had not met him previously, and I first met Glen's wife, Arlene, the day of his discharge.

That day, his return to outpatient hemodialysis had to be planned. Arlene told me she had arranged for a dialysis treatment after his discharge on Saturday, instead of waiting until the following week to resume his normal dialysis schedule of Monday, Wednesday and Friday. When I called the hemodialysis unit to confirm this, they told me he was scheduled for Monday. However, Arlene was adamant that Glen should receive dialysis on Saturday. I told her that I did not think dialysis was clinically indicated until the following week, but she did not accept this. As she spoke on Glen's behalf, he sat quietly, avoiding eye contact. She was clearly frustrated by the gaps in communication. She was direct, unrelenting and slightly hostile. She was not impressed by my ability to coordinate Glen's discharge. I remember feeling annoyed with her persistence, but I tried not to convey this.

I called the unit again, and a second nurse couldn't confirm a Saturday appointment, either. I was becoming frustrated and thought to myself that coordinating additional outpatient dialysis treatments for Glen was not high priority, as I still had 20 or so other patients to see that day - many with more acute medical issues. I finally called the phone number Arlene had for the dialysis unit, and to my surprise a nurse confirmed that Glen was scheduled for dialysis on Saturday, just as Arlene had said. I still don't know where the miscommunication originated between Arlene, myself and the dialysis unit. I suspect we had spoken to different nurses who weren't communicating with each other.

That evening, I remember feeling not great about our interaction; I thought I had come across as disengaged and uncompassionate, and I was frustrated by the miscommunication. I realized Arlene was concerned that Glen was at risk of volume overload if he did not receive dialysis over the weekend. I should have taken the time to ask Glen and Arlene why they felt dialysis on Saturday was critical, and clarified whom Arlene had spoken to about securing an extra treatment.

Three years later, I ran into Arlene at the annual meeting of Can-SOLVE-CKD Network; I had never expected to see her again. I was nervous about talking to her and worried about how she would describe our previous interactions to others at the meet- ing. When it was just the 2 of us together, she told me that Glen had passed away and she was grateful for the wonderful care he had received from his nephrologists in Winnipeg. The conversation ultimately turned to that last encounter.

We both apologized for our behaviour that day. I told her I wished I had taken the time to explore her concerns and better facilitate Glen's transition of care. She had taught me that patient and caregiver concerns, no matter how big or small they seemed to me, always need to be explored and not casually dismissed because of other pressing clinical demands. She told me that after I left the room, Glen had told her she "could not speak to doctors that way." I said I understood; she was advocating for her partner and should never apologize for doing that.

I am thankful for the opportunity to collaborate with Arlene on patient-oriented research, as she keeps Glen's legacy alive through her work as a patient partner.

\section{Competing interests: None declared.}

This article has been peer reviewed.

Affiliations: Department of Medicine (Collister), University of Manitoba, Winnipeg, Man.; Can-SOLVE CKD (Collister, Desjarlais), Vancouver, BC

Content licence: This is an Open Access article distributed in accordance with the terms of the Creative Commons Attribution (CC BY-NC-ND 4.0) licence, which permits use, distribution and reproduction in any medium, provided that the original publication is properly cited, the use is noncommercial (i.e., research or educational use), and no modifications or adaptations are made. See: https://creativecommons.org/licenses/by-nc-nd/4.0/

Acknowledgements: The authors thank Michelle Hampson and Leah Getchell for support in editing and submission.

Correspondence to: David Collister, dtcollister@gmail.com

360 Cases is a new type of Practice article that highlights the interpersonal and systemic aspects of health care that are seldom discussed in other Practice articles. Each comprises a brief case summary, followed by personal reflections from 2-4 people involved in the clinical encounter. One author must be a patient, family member or caregiver; the other authors may be anyone involved in the encounter (i.e, physicians, nurses, social workers, dietitians, etc.). For more information, see https://www.cmaj.ca/submissionguidelines or contact Victoria Saigle (Victoria.saigle@cmaj.ca). 